\title{
A novel method for calculating the energy cost of turning during running
}

This article was published in the following Dove Press journal:

Open Access Journal of Sports Medicine

8 May 2013

Number of times this article has been viewed

\author{
Yoichi Hatamoto' \\ Yosuke Yamada ${ }^{2}$ \\ Tatsuya Fujii ${ }^{3}$ \\ Yasuki Higaki ${ }^{3}$ \\ Akira Kiyonaga ${ }^{3}$ \\ Hiroaki Tanaka ${ }^{3}$ \\ 'Graduate School of Sports and \\ Health Science, Fukuoka University, \\ Nanakuma Jonan-ku Fukuoka, Japan; \\ ${ }^{2}$ The Fukuoka University Institute for \\ Physical Activity, Nanakuma Jonan-ku \\ Fukuoka, Japan; ${ }^{3}$ Faculty of Sports and \\ Health Science, Fukuoka University, \\ Nanakuma Jonan-ku Fukuoka, Japan
}

Correspondence: Hiroaki Tanaka Fukuoka University Institute for Physical Activity, 8-19-I Nanakuma Jonan-ku Fukuoka 8I4-0I80, Japan

Tel +8I 92 87| 663। ext 6750

$\mathrm{Fax}+8 \mid 928623033$

Email htanaka@fukuoka-u.ac.jp

\begin{abstract}
Although changes of direction are one of the essential locomotor patterns in ball sports, the physiological demand of turning during running has not been previously investigated. We proposed a novel approach by which to evaluate the physiological demand of turning. The purposes of this study were to establish a method of measuring the energy expenditure (EE) of a $180^{\circ}$ turn during running and to investigate the effect of two different running speeds on the $\mathrm{EE}$ of a $180^{\circ}$ turn. Eleven young, male participants performed measurement sessions at two different running speeds ( 4.3 and $5.4 \mathrm{~km} /$ hour). Each measurement session consisted of five trials, and each trial had a different frequency of turns. At both running speeds, as the turn frequency increased the gross oxygen consumption $\left(\mathrm{V} \cdot \mathrm{O}_{2}\right)$ also increased linearly $(4.3 \mathrm{~km} / \mathrm{hour}, r=0.973$; $5.4 \mathrm{~km} /$ hour, $r=0.996)$. The $\mathrm{V} \cdot \mathrm{O}_{2}$ of a turn at $5.4 \mathrm{~km} /$ hour $(0.55$ [SD 0.09$\left.] \mathrm{mL} / \mathrm{kg}\right)$ was higher than at $4.3 \mathrm{~km} /$ hour $(0.34$ [SD 0.13$] \mathrm{mL} / \mathrm{kg})(P<0.001)$. We conclude that the gross $\mathrm{V} \cdot \mathrm{O}_{2}$ of running at a fixed speed with turns is proportional to turn frequency and that the EE of a turn is different at different running speeds. The Different Frequency Accumulation Method is a useful tool for assessing the physiological demands of complex locomotor activity.
\end{abstract}

Keywords: energy expenditure, turning, turn frequency, running speed, $\mathrm{V} \cdot \mathrm{O}_{2}$, heart rate

\section{Introduction}

In ball games such as handball, basketball, rugby, and soccer, players frequently accelerate and decelerate to change direction, for example, in order to evade or overtake opponents. Most soccer players in the English Premier League make more than 700 turns per match. ${ }^{1}$ Turning while running requires modification of the locomotor pattern to direct the momentum of straight running in a new direction by applying an additional impulse to the ground. Because of the deceleration and acceleration of the center of mass that occurs with directional change, turns may impose more physiological demands on athletes than straight running. Although several previous studies have reported the biomechanical ${ }^{2,3}$ and/or medical ${ }^{4,5}$ aspects of turning during sports, studies of the physiological demand imposed on athletes by turning are limited. Some studies have examined the aerobic physiological demands of walking or running by analysis of expired gas, ${ }^{6,7}$ however, the energy expenditure (EE) required to perform a turn while running is currently unknown because it is difficult to evaluate. The objective of our study was to separate the EE of a turn from the EE of straight running by using the Different Frequency Accumulation Method, a novel approach combining the accumulation method with changing of turn frequency, to evaluate the instantaneous physiological demands of turning during running. 
Various graded tests have been conducted to estimate energy consumption during running; however, combining these tests with turning is an innovative approach. We hypothesized that if a person runs the same distance at a constant average speed, the gross EE will increase when turning while running compared to the EE of straight running. Gross EE can be expressed as the sum of the EE of turns plus the EE of straight running.

By using the Different Frequency Accumulation Method in this study, we established a method for the measurement of the $\mathrm{EE}$ of a $180^{\circ}$ turn during straight line running and examined whether the $\mathrm{EE}$ of a $180^{\circ}$ turn changes with different running speeds.

\section{Methods}

Ten recreationally active male volunteers participated in this study and the following information determined: mean age (22.8 [standard deviation (SD) 2.0] years), height (1.72 [SD 0.05] m), body mass (63.1 [SD 5.6] kg), and peak gross oxygen consumption (peak $\mathrm{V} \cdot \mathrm{O}_{2}$ ) (48.4 [SD 4.4] $\mathrm{mL} / \mathrm{kg} /$ minute). Aerobic capacity was measured using the incremental exercise test (peak $\mathrm{V} \cdot \mathrm{O}_{2}$ ) on a bicycle ergometer. Eight of the participants were experienced soccer players, and the remaining two had played rugby or volleyball regularly for more than 6 years. All were free of any injury that might influence their athletic performance.

This study was approved by the Ethical Committee of Fukuoka University, Fukuoka, Japan (number 10-02-02), and informed consent was obtained from all participants. This study followed the World Medical Association Declaration of Helsinki; Ethical Principles for Medical Research Involving Human Subjects; and Ethical Guidelines for Epidemiological Research by the Ministry of Education, Culture, Sports, Science, and Technology and the Ministry of Health, Labor, and Welfare, Japan.

All participants completed one familiarization session and two measurement sessions. We conducted the experiments in an indoor facility with flooring, and the participants were instructed to wear the same indoor sports shoes for all trials. On the day of the familiarization session, the participants were given instructions on performing the required turns while running using the sidestep cutting technique. ${ }^{2,3,8}$ The sidestep cutting technique involves the outgoing path proceeding away from the support leg side. Participants performed a turn for both legs, with an equal number of times for both the left and right legs. These movements were then practiced until the participants could consistently repeat the movement for the required time. All participants were instructed to avoid food, caffeine, tobacco products, and alcohol for 3 hours prior to the sessions.

Each measurement session consisted of five running trials of 5 minutes each at a fixed speed, with different running distances necessitating different turn frequencies. Running speeds for the two measurement sessions were $4.3 \mathrm{~km} /$ hour and $5.4 \mathrm{~km} /$ hour. Running distances for each trial were $3,3.6,4.5,6$, and $9 \mathrm{~m}$ (Figure 1), with the participants performing a $180^{\circ}$ turn after covering the required distance and repeating this for the full 5-minute period. The frequency of the turns for each running distance was $24,20,16,12$, and 8 times/minute at $4.3 \mathrm{~km} /$ hour and $30,25,20,15$, and 10 times/minute at $5.4 \mathrm{~km} /$ hour. Running speeds were controlled using a metronome (DM17 Seiko Digital Metronome; Seiko Corporation, Tokyo, Japan) that measured 2.00 seconds ( 60 beats per minute [bpm], 1 beat $=1$ second) for a speed of $5.4 \mathrm{~km} /$ hour and 2.50 seconds ( $50 \mathrm{bpm}, 1$ beat $=1.25$ seconds) for $4.3 \mathrm{~km} /$ hour for a distance of $3.0 \mathrm{~m}$. The metronome speed was adjusted for each particular case $(3.6 \mathrm{~m}, 2.40$ seconds [50 bpm] and 3.00 seconds [60 bpm]; $4.5 \mathrm{~m}, 3.00$ seconds [60 bpm] and 3.75 seconds [48 bpm]; $6.0 \mathrm{~m}, 4.00$ seconds and 5.00 seconds [both $60 \mathrm{bpm}$ ]; $9.0 \mathrm{~m}, 6.00$ seconds [60 bpm] and 7.50 seconds [ $48 \mathrm{bpm}$ ], for $5.4 \mathrm{~km} /$ hour and $4.3 \mathrm{~km} /$ hour, respectively). As long as they kept the pace indicated by

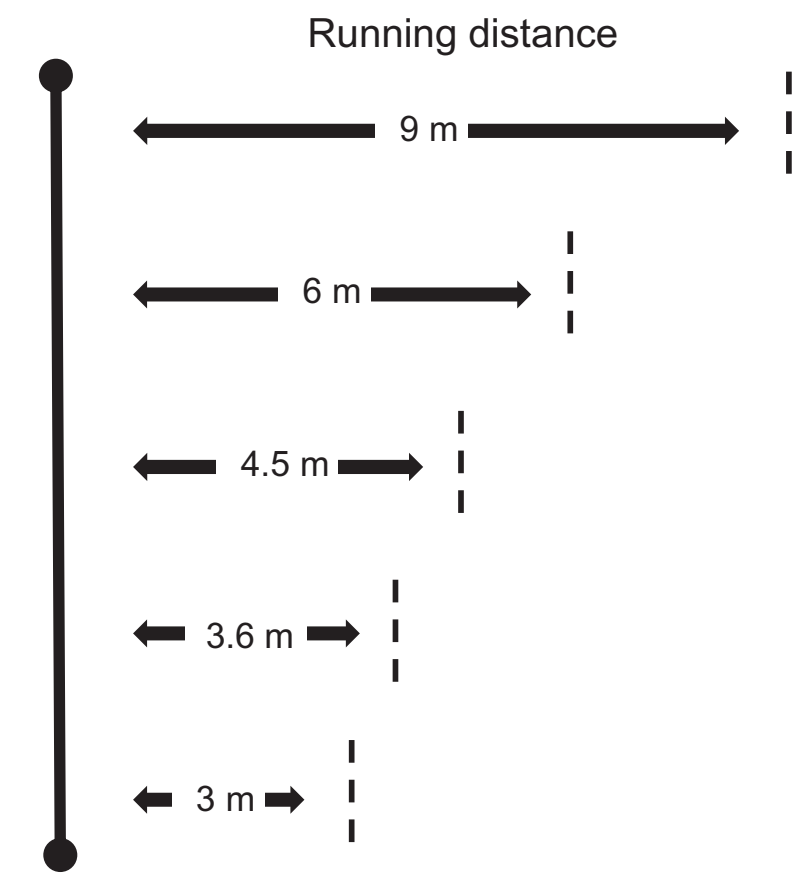

Figure I Course outline showing the running distances for each set. Note: Participants ran back and forth between two lines at running speeds of 4.3 and $5.4 \mathrm{~km} / \mathrm{hour}$. 
the metronome, the participants were allowed to use their own preferred stride frequency as it has been shown that this results in the lowest oxygen consumption $\left(\mathrm{V} \cdot \mathrm{O}_{2}\right) \cdot{ }^{9,10}$ The order in which participants performed the trials was randomly determined, and participants rested at least 15 minutes between each trial.

We calculated the EE of a turn from the slope of the regression line for EE against turn frequency (Figure 2). The EE of a turn included the linear deceleration to slow down the forward velocity as the runner initiated the change in heading direction and the linear acceleration to get the runner back up to the target running speed after the body had been rotated. If the EE of one turn while running at a constant average speed is expressed by the coefficient $\alpha$, gross EE may be calculated using a linear regression model as follows:

Gross EE $(\mathrm{kJ} /$ minute $)=\alpha(\mathrm{kJ}) \times \mathrm{f}($ turn $/$ minute $)+$ Running $\mathrm{EE}(\mathrm{kJ} / \mathrm{minute})$,

where Gross EE is the gross energy expenditure, $\alpha$ is the $\mathrm{EE}$ of a $180^{\circ}$ turn, $\mathrm{f}$ is the turn frequency, and running EE is the EE at constant velocity (Figure 1 ). The coefficient $\alpha$ might differ at different running speeds because kinetic momentum and physical load increase with greater running velocity.

Heart rate (HR) was measured for the last minute of each 5-minute trial (representing a steady-state condition during exercise) with a Polar HR monitor (CE0537; Polar Electro, Kempele, Finland). After completing each trial, participants were asked to rate their perceived exertion (RPE) using the Borg Scale. ${ }^{11}$

We investigated the EE of a turn during running using the Different Frequency Accumulation Method. The EE during each running trial was measured by collecting an expired gas



Frequency of turn movements (times/minute)

Figure 2 Relationship between gross EE and turn frequency.

Abbreviations: $\mathrm{EE}$, energy expenditure; $\alpha$, $\mathrm{EE}$ of a $180^{\circ}$ turn at one running speed; $f$, turn frequency; running $\mathrm{EE}$, the $\mathrm{EE}$ at constant velocity. sample through a facemask. Respiratory gas analysis was conducted using the mixing chamber method ${ }^{12,13}$ to evaluate the volume of expired air, and the $\mathrm{O}_{2}$ and $\mathrm{CO}_{2}$ fractions were analyzed by mass spectrometry (ARCO 2000; ARCO System, Chiba, Japan) every 12 seconds and averaged to 1 minute. At the beginning of each trial the metabolic system was calibrated using a 3-L calibration syringe for volume calibration and two different gas mixtures of known concentrations $\left(20.93 \% \mathrm{O}_{2}\right.$ and $0.04 \% \mathrm{CO}_{2} ; 15.00 \% \mathrm{O}_{2}$ and $4.55 \% \mathrm{CO}_{2}$ ) for calibration of the gas analyzers. Oxygen consumption $\left(\mathrm{V} \cdot \mathrm{O}_{2}\right)$ was assessed for the final 2 minutes of each running trial, and the average $\mathrm{V} \cdot \mathrm{O}_{2}(\mathrm{~mL} / \mathrm{kg} / \mathrm{minute})$ over those 2 minutes was calculated. The EE $(\mathrm{kJ})$ was estimated from respiratory exchange data using the equation of Lusk. ${ }^{14}$

Results are given as the mean (SD). Linear regression analyses were applied to calculate slopes and intercepts and 95\% confidence intervals (CI) were calculated. Two-way analysis of variance was used to compare the slope of the $\mathrm{V} \cdot \mathrm{O}_{2}$ of a turn, HR, and RPE obtained at the two different running speeds (4.3 and $5.4 \mathrm{~km} /$ hour $\times$ turn frequencies). Differences were considered significant at an $\alpha$ level of $P<0.05$. All statistics were conducted by SPSS software (v20; IBM Corporation, Armonk, NY, USA).

\section{Results}

All participants successfully completed both measurement sessions. At both running speeds, as the turn frequency increased the $\mathrm{V} \cdot \mathrm{O}_{2}, \mathrm{HR}$, and $\mathrm{RPE}$ of turning also increased (Figure 3 ). There was a significant correlation between $\mathrm{V} \cdot \mathrm{O}_{2}$ and turn frequency (mean $r=0.973$ and $r=0.996$ at $4.3 \mathrm{~km} /$ hour and $5.4 \mathrm{~km} /$ hour, respectively). The mean $\mathrm{V} \cdot \mathrm{O}_{2} \mathrm{~mL} / \mathrm{kg}$ of a turning was $\sim 0.34$ (SD 0.13, 95\% CI: 0.193-0.492) at $4.3 \mathrm{~km} /$ hour, and $0.55(0.09,95 \% \mathrm{CI}: 0.467-0.641)$ at a $5.4 \mathrm{~km} /$ hour running speed. The difference in the mean $\mathrm{V} \cdot \mathrm{O}_{2}$ of a turn between the 4.3 and $5.4 \mathrm{~km} /$ hour running speeds was statistically significant $(P<0.001)$. The slopes of the regression equations of HR versus turn frequency at each running speed were significantly different $(P<0.001)$, but the slopes of the regression equations of RPE versus turn frequency did not significantly differ at different running speeds $(P=0.390)$. The physiological demand of a single turn was 7.2 (SD 2.9) and 12.0 (SD 2.1) J/kg at 4.3 and $5.4 \mathrm{~km} /$ hour, respectively.

\section{Discussion}

The objectives of this study were to establish a technique for the measurement of the $\mathrm{EE}$ of a $180^{\circ}$ turn during running and to investigate the effect of different running speeds on the EE of 

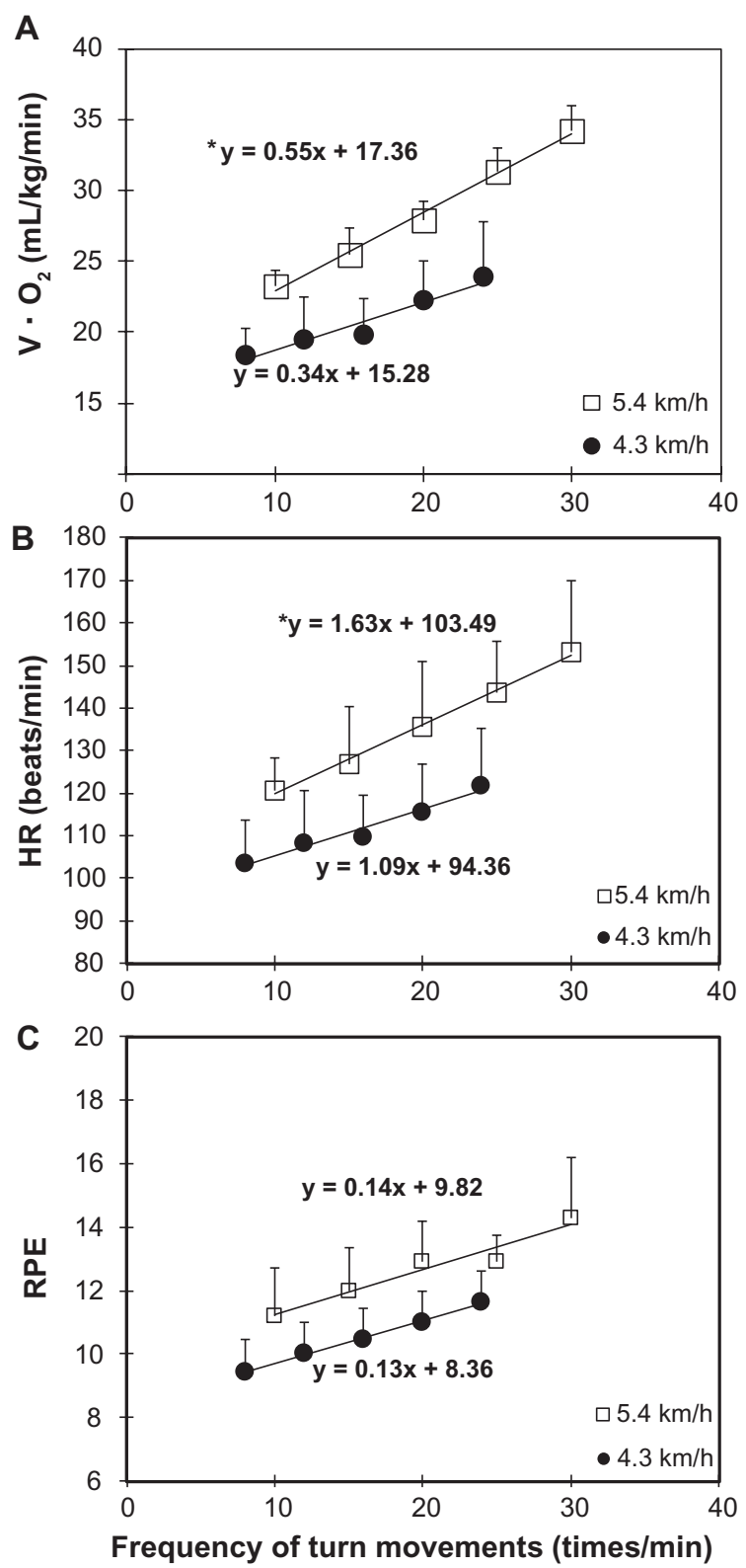

Figure 3 Relationship between turn frequency and oxygen consumption (A), heart rate (B), and RPE (C), while running at different speeds.

Notes: The slopes of the regression equations for $\mathrm{V} \cdot \mathrm{O}_{2}$ versus turn frequency and $H R$ versus turn frequency were significantly different at running speeds of 4.4 and $5.4 \mathrm{~km} /$ hour $(* P<0.00 \mathrm{I})$. The slopes of the regression equations for RPE versus turn frequency did not differ significantly at different speeds $(P=0.390)$.

Abbreviations: $\mathrm{HR}$, heart rate; RPE, rated perceived exertion; $V \cdot \mathrm{O}_{2}$, gross oxygen consumption.

a $180^{\circ}$ turn. The results of this study indicate that gross $\mathrm{V} \cdot \mathrm{O}_{2}$ increased linearly as turn frequency increased. In addition, the $\mathrm{V} \cdot \mathrm{O}_{2}$ of a turn was significantly higher at a higher running speed (Figure 3).

The results of this study show that the EE of turning during running can be calculated using the Different Frequency Accumulation Method. As this is the first study to quantify the physiological demands of turning during running, we cannot directly compare our results with those of other studies. However, some previous studies have addressed related topics. Preplanned cutting tasks during running have been shown to increase biomechanical load when compared with straight running. ${ }^{2,4,5}$ A $90^{\circ}$ change in direction while running showed a significantly larger vertical, braking, and propelling force compared to a $45^{\circ}$ change in direction. A sharper angle of turning would require a higher EE. Turning while running requires deceleration and acceleration movements and muscle work in eccentric and concentric muscular contraction. ${ }^{15}$ Eccentric muscle effort associated with deceleration would increase energy cost. The estimated energy cost in the acceleration phase of running is higher than the energy cost while running at a constant speed. ${ }^{16}$ The results of these studies suggest that a greater EE would occur during turning than during straight running. In addition, Dellal et al ${ }^{17}$ compared physiological responses of classical in-line intermittent exercise (running straight forward) with those of a specific intermittent shuttle exercise with $180^{\circ}$ directional changes at the same average running speeds. They reported that $\mathrm{HR}$, blood lactate, and RPE were significantly higher in the intermittent shuttle exercise that included $180^{\circ}$ turns than in in-line running and concluded that shuttle exercise increased physiological responses possibly because turning needs additional muscular action to that required in deceleration and acceleration. Our results demonstrate that $\mathrm{V} \cdot \mathrm{O}_{2}, \mathrm{HR}$, and RPE increase linearly as turn frequency increases; this confirms that turning during running generates higher physiological demands than straight running.

Our results show that the EE required for a $180^{\circ}$ turn at $5.4 \mathrm{~km} /$ hour is significantly higher than the EE required for a turn while running at $4.3 \mathrm{~km} /$ hour $(P<0.001)$. The $180^{\circ}$ turn has both an acceleration and deceleration phase, and the $\mathrm{EE}$ in the acceleration phase during running depends on the acceleration rate. ${ }^{16}$ As a high magnitude of horizontal propulsion is required to achieve high acceleration rates, ${ }^{18}$ the acceleration change is greater when performing a $180^{\circ}$ turn at higher running speeds. Therefore, turns at faster running speeds demand more EE. This is supported by our finding that HR increased more with increased turning frequency at running speeds of $5.4 \mathrm{~km} /$ hour than at $4.3 \mathrm{~km} /$ hour $(P<0.001)$, indicating that the physiological demand of turning is greater at the higher running speed. However, there was no statistically significant difference in the relationship between RPE and turn frequency at different running speeds $(P=0.390)$. This may be due to the relatively low running speeds that we used in this study, which might not impose heavy physiological loads that would be perceived as significantly increased exertion 
by the athletic participants. The relationship between the psychological and physiological demands of turning at various running speeds needs further investigation.

The $180^{\circ}$ turn technique is likely to be more efficient in ball game players who turn frequently than in those who do not. The value of $\mathrm{V} \cdot \mathrm{O}_{2}$ max using a shuttle run test in longdistance runners was underestimated compared with values obtained using a treadmill protocol. ${ }^{19}$ The shuttle run test includes repeated turning movements, and these movements were unfamiliar for long-distance runners. It is likely that the turn technique could result in differences in EE of a turn. Nine soccer players and one volleyball player were the subjects in this study. Although football players perform turns more frequently compared with volleyball players, the $\mathrm{EE}$ of a turn was not significantly different. The reason for this may be the running speed of the subjects. The difference in the EE of turning would likely be more evident when running speed is increased. For ball game players who turn frequently, turn efficiency may be important to save energy and to help improve performance during a game.

We hypothesized that the intercept of the regression line of $\mathrm{V} \cdot \mathrm{O}_{2}$ versus turn frequency can be considered the $\mathrm{V} \cdot \mathrm{O}_{2}$ at a constant running speed without turning on a flat road. Although we did not measure the $\mathrm{V} \cdot \mathrm{O}_{2}$ of running on a flat road without turning, the $\mathrm{V} \cdot \mathrm{O}_{2}$ predicted in the present study is comparable to previously reported values of $\mathrm{V} \cdot \mathrm{O}_{2}$ during running. The American College of Sports Medicine (ACSM) guidelines provide formulas to estimate $\mathrm{V} \cdot \mathrm{O}_{2}$ for walking and running speeds on a treadmill. ${ }^{20}$ We compared our results with the $\mathrm{V} \cdot \mathrm{O}_{2}$ values obtained using these formulas because most exercise physiologists are familiar with the ACSM guidelines. We also compared the intercept value of our equation with Leger's equation..$^{21}$ Hall et a ${ }^{22}$ compared the actual $\mathrm{EE}$ for running with some of the published prediction equations for $\mathrm{EE}$ during running and reported that Leger's prediction equation model is the most accurate in young healthy populations, although the equation just slightly overestimates the actual EE. The $\mathrm{V} \cdot \mathrm{O}_{2}$ values predicted using the intercept of the $\mathrm{V} \cdot \mathrm{O}_{2}$ versus turn frequency regression line in the present study were 15.3 (1.7) and 17.4 (1.6) $\mathrm{mL} /$ minute $/ \mathrm{kg}$ (4.3 and $5.4 \mathrm{~km} /$ hour, respectively). The $\mathrm{V} \cdot \mathrm{O}_{2}$ values predicted by the ACSM formula were 17.9 and $21.5 \mathrm{~mL} / \mathrm{kg} /$ minute, which are higher than our data. The $\mathrm{V} \cdot \mathrm{O}_{2}$ of treadmill running has been reported as being higher than that of track running. ${ }^{23}$ Ruiz and Sherman reported that the ACSM metabolic equation significantly overestimated the oxygen cost of running. ${ }^{24} \mathrm{The} \mathrm{V} \cdot \mathrm{O}_{2}$ estimated by Leger's equation was 15.8 and $19.3 \mathrm{~mL} /$ minute $/ \mathrm{kg}$ for running speeds of 4.3 and $5.4 \mathrm{~km} /$ hour, respectively, which was slightly higher than our data but consistent with Hall's report. ${ }^{22}$ These are small differences, and the Different Frequency Accumulation Method seems to be a reasonable approach to evaluate the physiological demand of turning during running.

Previous studies have indicated that the EE calculated from distance covered and running speeds in a traditional video analysis system using published equations were underestimated when compared with the EE calculated using direct measurements of $\mathrm{V} \cdot \mathrm{O}_{2}$ in ball games, such as soccer (estimated EE 653 to $884 \mathrm{kcal}^{25}$ vs actual EE 1140 and $1195 \mathrm{kcal}^{26,27}$ ). This estimated value failed to account for the additional metabolic demands of turning, stopping, jumping, and tackling. ${ }^{27,28}$ We propose adding the value of EE for turning to the value of EE estimated for the running distance when calculating the total EE in a soccer match. English Premier League soccer players perform more than 700 turns per game. ${ }^{1}$ We estimated the value of EE from only the number of turns per match as about $140 \mathrm{kcal}$; however, this value is insufficient if soccer players made 700 turns with $180^{\circ}$ turns while running at $5.4 \mathrm{~km} /$ hour during a match. In recent years as technology has advanced, the development of tools, such as global positioning systems and multivideo analysis systems, has made it possible to track field players more easily and accurately. ${ }^{29,30}$ The results of our present study may be helpful for evaluating the physiological demand and estimating the EE of players more accurately using video analysis or GPS.

The limitation of this study was that the participants ran at only two low running speeds. During a match, soccer players run at speeds ranging from 0 to more than $25 \mathrm{~km} /$ hour. $^{25,29}$ Therefore, investigation of the physiological demands of turning at additional running speeds is necessary to confirm that our method is applicable in a match situation. In addition, because turns are made at variable angles during a soccer match, ${ }^{1}$ examining the influence of the turn angle $\left(0^{\circ}\right.$ to $\left.180^{\circ}\right)$ on physiological demands is also necessary. Once the relationship between the energy cost of turning, the running speed, and the turn angle are clarified, expanding the application of our Different Frequency Accumulation Method to the actual match situation will be practical.

\section{Conclusion}

As turn frequency increased while a constant average speed was maintained, the gross EE increased linearly. This indicates that a certain amount of $\mathrm{EE}$ is required when a turn is made at a set speed and that the physiological demands of complex locomotor activities, such as turning, can be quantified using our Different Frequency Accumulation Method. Our results also indicate that as the running speed increased, the $\mathrm{EE}$ required for a turn 
also increased. The physiological demand of a single turn was $7.2 \mathrm{~J} / \mathrm{kg}$ at $4.3 \mathrm{~km} /$ hour and $12.0 \mathrm{~J} / \mathrm{kg}$ at $5.4 \mathrm{~km} /$ hour. This is the first study to quantify the physiological demands of turning while running. This information may be helpful for estimating the EE of players in a match when using video analysis and for designing training programs that include turns.

\section{Acknowledgments}

We thank the members of the Laboratory of Exercise Physiology, Fukuoka University, Fukuoka, Japan, and we are also grateful to the participants in this study. This study was carried out with the support of the Fukuoka University Institute for Physical Activity, a Technology Scientific Research Budget Basic Research Grant (A19200049 Strategic Research Infrastructure) from the Japanese Government's Ministry of Education, Culture, Sports, Science and Technology, and a Global FU Program grant from Fukuoka University.

\section{Disclosure}

The authors report no conflicts of interest in this work.

\section{References}

1. Bloomfield J, Polman R, O’Donoghue P. Physical demands of different positions in FA Premier League soccer. J Sports Sci Med. 2007;6(1): 63-70.

2. Rand MK, Ohtsuki T. EMG analysis of lower limb muscles in humans during quick change in running directions. Gait Posture. 2000;12(2): 169-183.

3. Schot P, Dart J, Schuh M. Biomechanical analysis of two change-ofdirection maneuvers while running. J Orthop Sports Phys Ther. 1995; 22(6):254-258.

4. Besier TF, Lloyd DG, Cochrane JL, Ackland TR. External loading of the knee joint during running and cutting maneuvers. Med Sci Sports Exerc. 2001;33(7):1168-1175.

5. Besier TF, Lloyd DG, Ackland TR. Muscle activation strategies at the knee during running and cutting maneuvers. Med Sci Sports Exerc. 2003;35(1):119-127.

6. Browning RC, Kram R. Energetic cost and preferred speed of walking in obese vs normal weight women. Obes Res. 2005;13(5):891-899.

7. Mercier J, Le Gallais D, Durand M, Goudal C, Micallef JP, Préfaut C. Energy expenditure and cardiorespiratory responses at the transition between walking and running. Eur J Appl Physiol Occup Physiol. 1994; 69(6):525-529.

8. McLean SG, Lipfert SW, van den Bogert AJ. Effect of gender and defensive opponent on the biomechanics of sidestep cutting. Med Sci Sports Exerc. 2004;36(6):1008-1016.

9. Mercer J, Dolgan J, Griffin J, Bestwick A. The physiological importance of preferred stride frequency during running at difference speeds. JEP Online. 2008;11(3):26-32.

Open Access Journal of Sports Medicine

\section{Publish your work in this journal}

Open Access Journal of Sports Medicine is an international, peer-reviewed, open access journal publishing original research, reports, reviews and commentaries on all areas of sports medicine. The manuscript management system is completely online and includes a very quick and fair peer-review system.
10. Hogberg P. How do stride length and stride frequency influence the energy-output during running? Arbeitsphysiologie. 1952;14(6): 437-441.

11. Borg G. Perceived exertion as an indicator of somatic stress. Scand $J$ Rehabil Med. 1970;2(2):92-98.

12. Wilmore JH, Costill DL. Semiautomated systems approach to the assessment of oxygen uptake during exercise. J Appl Physiol. 1974;36(5):618-620.

13. Yoshimura E, Kumahara H, Tobina T, et al. Relationships between fat deposition in the liver and skeletal muscle and insulin sensitivity in Japanese individuals: a pilot study. Diabetes Metab Syndr Obes. 2011;20(4):35-43.

14. Lusk G. Animal calorimetry. Analysis of the oxidation of mixtures of carbohydrate and fat. J Biol Chem. 1924;59:41-42.

15. Sheppard JM, Young WB. Agility literature review: classifications, training and testing. J Sports Sci. 2006;24(9):919-932.

16. di Prampero PE, Fusi S, Sepulcri L, Morin JB, Belli A, Antonutto G. Sprint running: a new energetic approach. J Exp Biol. 2005;208(Pt 14): 2809-2816.

17. Dellal A, Keller D, Carling C, Chaouachi A, Wong dP, Chamari K. Physiologic effects of directional changes in intermittent exercise in soccer players. J Strength Cond Res. 2010;24(12):3219-3226.

18. Hunter JP, Marshall RN, McNair PJ. Relationships between ground reaction force impulse and kinematics of sprint-running acceleration. J Appl Biomech. 2005;21(1):31-43.

19. St Clair Gibson A, Broomhead S, Lambert MI, Hawley JA. Prediction of maximal oxygen uptake from a $20-\mathrm{m}$ shuttle run as measured directly in runners and squash players. J Sports Sci. 1998;16(4):331-335.

20. Mahler DA, Froelicher VF, Houston Miller N, York TD. American College of Sports Medicine. Guidelines for Exercise Testing and Prescription, 5th ed. Baltimore, MD: Lippincott Williams \& Wilkins; 1995:269-287.

21. Léger L, Mercier D. Gross energy cost of horizontal treadmill and track running. Sports Med. 1984;1(4):270-277.

22. Hall C, Figueroa A, Fernhall B, Kanaley JA. Energy expenditure of walking and running: comparison with prediction equations. Med Sci Sports Exerc. 2004;36(12):2128-2134.

23. Meyer T, Welter JP, Scharhag J, Kindermann W. Maximal oxygen uptake during field running does not exceed that measured during treadmill exercise. Eur J Appl Physiol. 2003;88(4-5):387-389.

24. Ruiz A, Sherman NW. An evaluation of the accuracy of the American College of Sports Medicine metabolic equation for estimating the oxygen cost of running. J Strength Cond Res. 1999;13(3):219-223.

25. Shephard RJ. The energy needs of a soccer player. Clin J Sport Med. 1992;2(1):62-70.

26. Miyagi O, Susa T, Kitagawa K. Physiological and movement characteristics during a game of soccer players. Descente Sports Science (in Japanese). 1997;18:231-238.

27. Seliger V. Energy metabolism in selected physical exercises. Int ZAngew Physiol. 1968;25(2):104-120.

28. Reilly T. Energetics of high-intensity exercise (soccer) with particular reference to fatigue. $J$ Sports Sci. 1997;15(3):257-263.

29. Dellal A, Chamari K, Wong DP, et al. Comparison of physical and technical performance in European soccer match-play: FA Premier League and La Liga. Eur J Sport Sci. 2011;11(1):51-59.

30. Wisbey B, Montgomery PG, Pyne DB, Rattray B. Quantifying movement demands of AFL football using GPS tracking. I Sci Med Sport. 2010;13(5):531-536.

\section{Dovepress}

Visit http://www.dovepress.com/testimonials.php to read real quotes from published authors. 